
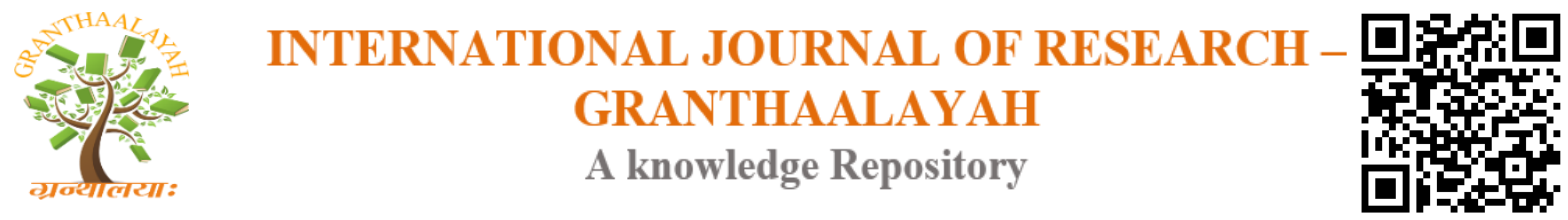

Social

\title{
VIEWSOF STUDENTS ON THE INCLUSION OF LEARNERS WITH DISABILITIES
}

\author{
Penda Annie ${ }^{1}$, Muvombo Moono ${ }^{2}$ \\ ${ }^{1,2}$ Kwame Nkrumah University P. O. Box 80404, Kabwe-Zambia
}

\begin{abstract}
This manuscript is about the study conducted in order to establish the views of students at Kwame Nkrumah University concerning the inclusion of learners with disabilities. Three objectives were administered, and these were to establish the views of students concerning the inclusion of learners with disabilities, to identify the benefits of inclusive education and to determine what should be done to promote inclusive education. The findings were that, there is positive treatment of learners with disabilities and that they are able to learn with others who are not disabled, they need modified curriculum and more resources, the environment is being modified bit by bit. It was also found that, some teaching methods being used are not suitable. Among the benefits realised from inclusive education which were established through the views of students were that, some learning materials are given to learners with disabilities, there is social and academic interaction between learners with and without disabilities, there is positive attitude towards learners with disabilities in inclusive setting, equality and the right to education are being realised. Concerning what has to be done to improve inclusive education students views were that there is need for awareness campaign about inclusive education, more learning materials are needed, modification of existing teaching methods and infrastructure is needed and positive language towards learners with disabilities is required. The semi-structured interview guide was administered when collecting data from fifteen respondents.
\end{abstract}

Keywords: Inclusive Education; Learners with Disabilities; Views; Students.

Cite This Article: Penda Annie, and Muvombo Moono. (2019). "VIEWSOF STUDENTS ON THE INCLUSION OF LEARNERS WITH DISABILITIES.” International Journal of Research - Granthaalayah, 7(3), 142-147. https://doi.org/10.29121/granthaalayah.v7.i3.2019.954.

\section{Introduction}

\subsection{Background}

Inclusive education is supported through advocacy by people, organizations such as NonGovernment Organisations and church organizations who fight for the rights of learners with special educational needs. The roles performed by advocacy group is that of fighting for rights of learners with special educational needs. They ensure that learners with special educational needs 
have access to quality education, improved technology systems and job opportunities. They also see to it that educational needs of learners with special educational needs are met. They can organize meetings on how to provide service to the learners with special needs and lobby for help on behalf of these learners in order to address their plight. Before advocating for inclusive education for learners with disabilities researchers had first to hear from the views of students of special education at Kwame Nkrumah about the matter, it is argued that, engaging views of students can lead to changes in the understanding of learners with disabilities and practices that are inclusive in nature and researchers would know how much has been done and what is not done which needs to be advocated for.

\subsection{Statement of the Problem}

Inclusive education has been introduced in institutions of learning in support of learners with disabilities. However, the views of students about inclusive education of learners with disability remain unknown. This study aimed at identifying the views of students on the inclusion of learners with disabilities.

\subsection{Study Objectives}

1) To establish the views of students concerning the inclusion of learners with disabilities.

2) To identify the benefits of inclusive education.

3) To determine what should be done to promote inclusive education.

\subsubsection{Study Questions}

1) What are the views of students concerning the inclusion of learners with disabilities?

2) What are the benefits of inclusive education?

3) What should be done to promote inclusive education?

\subsection{Purpose of the Study}

The purpose of this study was to establish the views of students concerning the inclusion of learners with disabilities.

\subsection{Significance of the Study}

It was hoped that the findings of this study would establish the views of students concerning the inclusion of learners with disabilities. It was also hoped that, its findings might be added to the body of knowledge on the views of students concerning the inclusion of learners with disabilities.

\section{Research Instrument/Sample Size}

The research conducted was qualitative in nature and researchers used semi-structured interview guide. The sample comprised of 15 students in fourth year who were undergoing studies in special education programme at bachelor's level at Kwame Nkrumah University. The semi-structured interview guide was administered to this sample. 


\subsection{Literature Review}

Deborah (2010) define inclusive education as a pairing of philosophy and teaching practices that allow each learner to feel respected, confident and safe to learn and develop to his or her potential because it is based on the values and beliefs centered on the best interest of the learner that which promotes social cohesion, belonging and active participation in learning and positive interaction with peers in the school community. The definition highlight the issues of good social sense of inclusive education which aim at overcoming segregation which teaches learners with special needs to be fearful, ignorant and breeds prejudice. In this case inclusive education promotes that, all students need an education that helps them develop relationships and prepare them for life in the mainstream society. It is believed that, only inclusion has the potential to reduce fear and to build friendship, respect and understanding among learners with special needs. The other aspect being heighted by the definition is the issue of inclusive education as good education because learners with disabilities benefit and do better academically in inclusive settings. Ainsoow and Messiou, (2017) argued that, engaging views of students can lead to changes and global development in the understanding of learners with disabilities and practices that are inclusive in nature. This is true in the sense that new ideas and approaches can be developed which can be of help in addressing some challenges that may be encountered under inclusive learning. The trend of including learners with disabilities in general education is on increase and some of the benefits of inclusive education are being realised in the lives of learners with disabilities. According to Mag et al (2017) Inclusive education is a child's right not a privilege and many children with disabilities have been silenced and excluded from education thus inclusive education is real and urgent need for all education system around the world. In other words learners with disabilities need not to be silenced or excluded from education because it is their right to be included. Vinorao, (2016) pointed out some of the benefits of inclusive education such as development of friendship with peers and others, removal of barrier to participation and learning and having access to adaptive as well as general curriculum. However, inclusive education has posed some challenges such as lack of time combined with difficulties educators' encounter of balancing the demands of all learners, class size, lack of appropriate teaching resources, behaviour problem exhibited by some learners resulting in constant behaviour management and lack of appropriateness in the area of inclusive education methods (Westwood and Graham, 2009). In order to promote inclusive education there is need for positive attitude, conducive learning environment, supportive policy and leadership, flexible curriculum, pedagogy, school and classroom processes based on research and community involvement, necessary training and resources (Loreman, 2007).

\section{Results}

The findings are presented in line with the study objectives. The views of students concerning inclusive education of learners with disabilities were as follows: One respondent reported that, learners with disabilities need to learn together with those without disabilities but teaching method being used is not effective to them. Another response from another respondent was that inclusive education is workable to learners with disabilities in the sense that before it most of them were left uneducated or abandoned. Another response was voiced that, inclusive education is workable because learners with disabilities are treated in the same manner as with those without disabilities are treated. It is possible to include learners with disabilities in the general education with the modified curriculum however it can be partially implemented in terms of learning material 
resources as responded by one respondent. The other response was that, there is no stigmatization under inclusive education towards learners with disabilities. Learners with disabilities are able to access education with less difficulties as echoed by one respondent. .Another response was that, learners with disabilities are able to access education like other learners without disabilities under inclusive education. The other response was that, inclusive education is workable because school infrastructure is being modified bit by bit although on the other hand most buildings are not accessible to learners with disabilities.

Concerning the benefits of inclusive education to learners with disabilities the responses were as follows: the response from one respondent was that, learners with disabilities are given some learning materials such as braille paper. Another response was that, learners without disabilities are able to interact socially and academically with those with disabilities and they treat them well. The other response was that, learners without disabilities develop positive attitude towards learners with disabilities through interaction and it was echoed that 'we no longer look down on any of them'. It also reported that, it brings about equality, motivation and encouragement to learners with disabilities because they benefit a lot academically such as in terms of skills. Knowledge and concepts, they also gain new friends who are not disabled and develop self-esteem and confidence. Another response was that it is a good opportunity to learners without disabilities to learn on how to handle the learners with disabilities.

The responses concerning the third objective on what has to be done to improve inclusive education were as follows: one response was that, awareness about the disabilities should be encouraged to others without disabilities. The other response was that, necessary and enough learning materials should be provided. Another response was that, there is need to keep on improving the existing infrastructure in order provided conducive infrastructure such as toilets, classrooms and doorways. The other response was echoed that, positive language towards learners with disabilities needs to be encouraged. Then another response was stated that, there is need to use suitable teaching method depending on the disability of a learner. The response from one participant was reported that, there is need to provide learning materials. Then one student stated that, infrastructure should be conducive.

\subsection{Discussion of Results}

The discussion of the findings was be based on the objectives of the study and these were to establish the views of students concerning the inclusion of learners with disabilities, to identity the benefits of inclusive education and determining what should be done to promote inclusive education.

\section{Establishing the Views of Students Concerning the Inclusion of Learners with Disabilities}

The findings concerning the views of students on the inclusion of learners with disabilities were that, inclusive education is workable because learners with disabilities are treated in the same manner as with those without disabilities are treated and they are not stigmatized. It is also workable to learners with disabilities in the sense that before it most of them were left uneducated or abandoned. It is possible to include learners with disabilities in the general education with the modified curriculum however it is being partially implemented because learning material resources are not enough. The other view was that, learners with disabilities need to learn together with those 
without disabilities. Then another view was that, inclusive education is being realized because school infrastructure is being modified bit by bit although most buildings are not accessible to learners with disabilities. As inclusive education is being implemented the students' view was that, teaching methods used are not suitable. The views of students on inclusive education practice were cardinal and Ainsoow and Messiou, (2017) argued that, engaging views of students can lead to changes and global development in the understanding of learners with disabilities and practices that are inclusive in nature. This is true in the sense that new ideas and approaches can be developed which can be of help in addressing some challenges that may be encountered under inclusive learning. The researchers were in agreement with the two authors because the current views from students has revealed that inclusive education is good and it is at the initial stage of being implemented of course while experiencing challenges which calls for critical attention from the proponents of inclusive education for it to be implemented fully.

\section{Identification of the Benefits of Inclusive Education}

The study found the following benefits of inclusive education; for instance learners with disabilities were reported to have been given some learning materials such as braille paper. Another discovery was that, learners without disabilities were able to interact socially and academically with those with disabilities and they treat them well. The other finding was that, learners without disabilities developed positive attitude towards learners with disabilities through interaction and it was echoed by those without disabilities that 'we no longer look down on any of them'. Another finding from this study was that, inclusive education brings about equality, motivation and encouragement to learners with disabilities because they benefit a lot academically in terms of skills, knowledge and concepts they also gain new friends who are not disabled and develop self-esteem and confidence. Another discovery was that inclusive education gives a good opportunity to learners without disabilities to learn on how to handle the learners with disabilities. The current findings are similar to the findings of Vinorao, (2016) who pointed out some of the benefits of inclusive education as development of friendship with peers and others, removal of barrier to participation and learning and having access to adaptive as well as general curriculum. The benefits of inclusive education pointed to one thing which is the child's right to education. This is supported by Mag et al (2017) who stated that, inclusive education is a child's right not a privilege and many children with disabilities have been silenced and excluded from education thus inclusive education is real and urgent need for all education system around the world. In other words learners with disabilities need not to be silenced or excluded from education because it is their right to be included. The researchers are of the view that, basing on the findings of this study, inclusive education is beginning to take shape and its fruits are being realized in the lives of both learners with disabilities and those without disabilities in terms of social and academic skills, concepts and knowledge and above all their right is being granted to them.

\section{Determining What Should be Done to Promote Inclusive Education}

It was discovered that, in order to promote inclusive education awareness about the disabilities should be encouraged to others without disabilities. The other finding was that, necessary learning materials should be provided and the need to use suitable learning method or modifying the existing methods depending on the disability of a learner. Another discovery was the need to keep on improving the existing infrastructure in order to provide conducive infrastructure such as toilets, classrooms and doorways. It was found that, positive language towards learners with disabilities needs to be encouraged. The finding of this study from student point of view concerning what has 
to be done in order to promote inclusive education was similar on some issue to what was found by Loreman, (2007).who stated that, in order to promote inclusive education there is need for positive attitude, conducive learning environment, supportive policy and leadership, flexible curriculum, pedagogy, school and classroom processes based on research and community involvement, necessary training and resources. For instance, issues like need for positive attitude, conducive learning environment, pedagogy and need for resources were similar to the finding of this study. However, issues like supportive policy and leadership, flexible curriculum, school and classroom processes based on research and community involvement and necessary training were not discovered in the current study which are also necessary. The researchers' point of view was that, views from students were necessary if implemented can contribute to full realization of inclusive education. The other view from other researchers are also necessary and they are being realized in Zambia bit by bit for example, the training of specialist teachers is on-going and supportive policy is in place.

\section{Conclusion}

Basing on the discussions of this study, the views of students concerning the inclusion of learners with disabilities were established such as there was positive treatment of learners with disabilities, learners with disabilities were able to learn with others who were not disabled, , learners with disabilities need modified curriculum and more resources, the environment is being modified bit by bit, teaching method being used are not suitable to some learners with disabilities. Among the benefits realised from inclusive education which were established through the views of students were that, some learning materials were given to learners with disabilities, there was social and academic interaction between learners with and without disabilities, there was positive attitude towards learners with disabilities in inclusive setting, equality and the right to education were being realised. Concerning what has to be done to improve inclusive education students views were that there was need for awareness campaign about inclusive education, more learning materials were needed, modification of existing teaching methods and infrastructure were needed and positive language towards learners with disabilities was required.

\section{References}

[1] Ainsoow, M and Messiou, K. (2017). Enganging with views of students to promote inclusion in Education . Journal of education change.19 (2) p356.

[2] Deborah,D.H. (2010) "Introduction to special education" 7th ed. New Jersey; Merril.

[3] Loreman, T. (2007). Seven pillars for inclusive education Moving form why to how. https;//www.researchgate.net.publication. Accessed on 3/3/19

[4] Mag, A.G., Sinfield, S and Burns, T, (2017). The benefits of inclusive education: new challenges for university teachers

[5] Vinodirao, S. (2016). Benefits of inclusive education for student with intellectual disabilities. https://www.questia.com.library.journal. Accessed on 3/3/19.

[6] Westwood, P and Graham, L (2009). Inclusion of students with special needs; Benefits and Obstacles perceived by teachers in new South Wales and South Australia. Australian Journal of learning disabilities. 8(1) Pp3-15

*Corresponding author.

E-mail address: muvombomoono22@ gmail.com 